Article

\title{
Low Lactic Acid-Producing Strain of Lachancea thermotolerans as a New Starter for Beer Production
}

\author{
Marek Zdaniewicz *(D), Paweł Satora, Aneta Pater ${ }^{\mathbb{D}}$ and Sylwia Bogacz \\ Department of Fermentation Technology and Microbiology, Faculty of Food Technology, \\ University of Agriculture in Krakow, 31-120 Krakow, Poland; pawel.satora@urk.edu.pl (P.S.); \\ a.pater@urk.edu.pl (A.P.); sylwiabogacz123@wp.pl (S.B.) \\ * Correspondence: m.zdaniewicz@urk.edu.pl
}

Received: 27 December 2019; Accepted: 5 February 2020; Published: 7 February 2020

\begin{abstract}
Growing consumer interest in new beer flavors is contributing to the application of innovative materials and non-Saccharomyces yeast in brewing. The goal of this study was to test the impact of the low lactic acid-producing Lachancea thermotolerans MN477031 strain on the process of fermenting beer wort, with two different concentrations of bitter compounds, and on the quality of the beer produced. Qualify factors were broadly analyzed, including ethanol content, apparent degree of fermentation, sugars, organic acids, free amino nitrogen, glycerol, volatile compounds, ions and so on. It was proven that the L. thermotolerans MN477031 strain demonstrated a high capacity for rapid initiation of wort fermentation, and a tolerance to hop-derived compounds. As a result, the alcohol content in beer from this method of production was approximately $20 \%$ lower, while the content of the real extract was significantly higher in comparison to commercial Safbrew T-58. This strain stands out from many strains of $L$. thermotolerans due to the low lactic acid production and only marginal influence on $\mathrm{pH}$ decrease compared to Saccharomyces cerevisiae. Therefore, the potential of MN477031 in the production of different types of beer (not only sour) is very high. The composition of volatile compounds in L. thermotolerans beer differs-not only in terms of the use of the strain, but also in hop variety.
\end{abstract}

Keywords: beer; wort; fermentation; FAN; yeast; non-Saccharomyces; Lachancea thermotolerans

\section{Introduction}

A growing interest in craft beer and its production has contributed to an increase in the number of microbreweries. This trend is particularly very strong in Europe [1] and the USA [2]. According to the Alltech Survey [3], in 2017, out of over 19,000 breweries around the world, craft breweries represented $94 \%$. They owe their popularity largely to their wide variety and original styles on offer. Frequently, in an effort to develop interesting beer flavors, sugar sources other than barley malt are used (e.g., lentil [4], buckwheat [5], triticale [6], oats [7], black rice [8]). Another method of influencing organoleptic characteristics is through enriching beer with new, herb-derived aromas, as well as other aromas originating from biological materials [9]. A recent and very promising method of creating unique beer has been the application of non-Saccharomyces strains, known from the wine industry, in combination with brewing technology. This may result in beer with a desirable physiochemical composition and unique flavor profile. It should also be noted that non-Saccharomyces yeasts have been used in beer production from the onset as a component of spontaneous fermentation microbiota [10]. Through their metabolic, physiological or cellular functions, these microorganisms significantly change the organoleptic properties of food products [11].

The effect of many non-Saccharomyces yeast strains on the brewing process has been previously reported [12]. Most of the studied yeasts had low alcohol production efficiency (e.g., Torulaspora 
delbrueckii [13-15], Brettanomyces bruxellensis, Pichia kluyverii [16], Wickerhamomyces anomalus [17], Lachancea fermentati [18]) which made them a very good material for the production of low-alcohol or alcohol-free beer [12]. In order to increase the efficiency of the fermentation, they were also used as mixed cultures with Saccharomyces, obtaining promising results comparable with pure Saccharomyces [14]. Producing beer with an average alcohol content (ca. 4-6\% v/v) through using pure non-Saccharomyces yeast requires the use of strains with the ability to ferment maltose (e.g., Lachancea thermotolerans [19], or Zygotorulaspora florentina [16], etc.).

L. thermotolerans is an innovative representative of non-Saccharomyces cultures. First known as Kluyveromyces thermotolerans, it was separated from the other species of Kluyveromyces due to significant metabolic and genetic differences $[11,20]$. The strain is very common, occurring in different environments both natural and artificial. Furthermore, it is recognized that $L$. thermotolerans strains produce lactic acid in large quantities during alcohol fermentation, with a capacity of up to $16 \mathrm{~g} / \mathrm{L}$ of product $[21,22]$, moreover improving the aroma of beer through inter alia, high ethyl butyrate and ethyl acetate production in both pure and mixed fermentations [17]. These distinctive properties are characteristic for the known L. thermotolerans yeast when compared with many other microorganisms $[23,24]$. On the other hand, significant lowering of beer $\mathrm{pH}$ by some Lt strains (e.g., 0.6, as a result of lactic acid production [14]), can limit their use at tailoring flavors during the production of various styles of beers.

The aim of the present study was to determine the low lactic acid production efficiency of the new L. thermotolerans MN477031 strain for brewing. Important parameters such as fermentation performance, resistance to hop compounds, sugar and nitrogen compound utilization and selected metal ions were reported. Furthermore, the new beer profile was compared to the reference trial (S. cerevisiae) by contrasting the interaction of the new yeast strain with different varieties of hop. Demonstrating the positive brewing properties of the yeast may prompt a wider application in the brewing industry of the L. thermotolerans MN477031.

\section{Materials and Methods}

\subsection{Materials}

\subsubsection{Yeast Strains}

The L. thermotolerans strain MN477031 yeast $(\mathrm{Lt})$ was isolated from grape must in Slovakia and used for fermentation. It was previously identified and characterized by 2.6. 5.8S-ITS rRNA gene region sequencing (GenBank NCBI database accession number MN477031). The S. cerevisiae (Sc) yeast of the Safbrew T-58 strain (Fermentis Division of S.I.Lesaffre, Marcq-en-Baroeul, France) was used as a reference sample due to it having a fermentation temperature similar to Lt along with a high amount of spice and a fruity compound production.

\subsubsection{Hops}

The Polish hop varieties were Lubelski (2.7\% alpha acids) and Marynka (7.4\% alpha acids) (Polish Hops, Karczmiska Pierwsze, Poland) were used.

\subsection{Methods}

\subsubsection{Wort Production}

All-malt, first worts $(18.6 \%)$ were produced by infusion mashing in a craft brewery from pilsner malt (Ireks, Kulmbach, Germany). After lautering, worts were standardized to a $12 \%$ extract with distilled water, and $250 \mathrm{~mL}$ of the wort was boiled in lab conditions for an hour with reflux condensers (to reduce vaporization). At the beginning of boiling, the Polish hops variety Lubelski (2.7\% alpha acids) and Marynka (7.4\% alpha acids) were dosed at 5 and $2 \mathrm{~g} / \mathrm{L}$, respectively. After boiling, the hot trub was removed from the worts; subsequently, the samples were cooled to $20^{\circ} \mathrm{C}$. Before inoculation, 
the key quality parameters of the worts were analyzed. The strongly significant differences between worts were only related to parameters of hop origin (Table 1). The values of obtained International Bitterness Unit (IBU) were 40 and 53 for Lubelski and Marynka hopped worts, respectively. The level of the extract, maltose (as the main wort sugar), glucose and free amino nitrogen (FAN) content were similar among the worts.

Table 1. The composition of worts before fermentation, depending on the hop variety used.

\begin{tabular}{cccccc}
\hline & Extract & Glucose & Maltose & FAN & \multirow{2}{*}{ IBU } \\
\cline { 2 - 5 } & $\% \mathbf{~ ( w / w ) ~}$ & \multicolumn{2}{c}{$\mathbf{g} / \mathbf{L}$} & $\mathbf{m g} / \mathbf{L}$ & \\
\hline Lubelski & $12.0 \pm 0.02$ & $12.52 \pm 0.75$ & $79.40 \pm 4.71$ & $131.07 \pm 0.92$ & $40 \pm 2^{\text {a }}$ \\
Marynka & $12.0 \pm 0.03$ & $14.49 \pm 2.58$ & $83.03 \pm 6.29$ & $139.18 \pm 0.77$ & $53 \pm 3^{\mathrm{b}}$ \\
Sig. $^{1}$ & ns & ns & ns & ns & $* * *$ \\
\hline
\end{tabular}

${ }^{1}$ Sig.: significance; ${ }^{* * *}$ display the significance at $0.5 \%$ by least significant difference; ns: not significant. Values with different superscript roman letters (a-b) in the same column are significantly different according to the Tukey's range test $(p<0.05)$. International Bitterness Unit (IBU); and free amino nitrogen (FAN).

\subsubsection{Yeasts Propagation and Fermentation}

All yeast strains were maintained on Sabouraud Dextrose LAB-AGAR (Biocorp, Warsaw, Poland) plates at $5{ }^{\circ} \mathrm{C}$. Yeasts growing for $24 \mathrm{~h}$ on Sabouraud Dextrose LAB-AGAR at $25{ }^{\circ} \mathrm{C}$ were picked into a flask containing $20 \mathrm{~mL}$ of liquid Sabouraud broth (Biocorp, Warsaw, Poland) and grown at $25^{\circ} \mathrm{C}$ for 2 days on a rotary shaker shaking at $121 \mathrm{rpm}$. After that the yeasts were centrifuged $(735 \times g)$ for $15 \mathrm{~min}$, washed with sterile distilled water, centrifuged again, and suspended in $10 \mathrm{~mL}$ of hopped wort (Marynka, Lubelski). The amount of cells in $1 \mathrm{~mL}$ of suspension was evaluated using the Thoma chamber (in triplicate).

Marynka (M (100 mL))- and Lubelski (L (100 mL))-hopped worts were inoculated with L. thermotolerans $(\mathrm{Lt})$ or $S$. cerevisiae $(\mathrm{Sc})$ yeast cell suspensions to obtain $7.65 \times 10^{6}$ cells $/ \mathrm{mL}$, and fermented in rubber-stoppered Erlenmeyer flasks with fermentation tubes. The samples were fermented at $20^{\circ} \mathrm{C}$ in a Q-CELL thermostatic chamber with daily measurements of weight loss. All activities were performed in sterile conditions.

\subsubsection{Analytical Determinations}

Ethanol, real extract and apparent degree of fermentation (ADF) were measured by the automatic wort and beer analyzer (Alcolyzer, Anton Paar DMA 4500+). A sample of degassed beer was mixed with diatomaceous earth and filtered through a paper filter to obtain $\sim 50 \mathrm{~mL}$ of filtrate. The filtrate was degassed for $20 \mathrm{~min}$ (universal shaker, $150 \mathrm{rpm}$ ), adjusted to $20^{\circ} \mathrm{C}$ and filtered again.

The $\mathrm{pH}$ of the beers was measured using the Mettler Toledo FiveGo $\mathrm{pH}$-meter.

Volatile compound analysis (SPME-GC-MS): In order to determine the headspace volatile compounds, $1 \mathrm{~g}$ of $\mathrm{NaCl}$ and a $2-\mathrm{mL}$ sample of wort/beer were placed into a $10-\mathrm{mL}$ vial. Next, an internal standard solution was added $(0.57 \mathrm{mg} / \mathrm{L}$ 4-methyl-2-pentanol, $0.2 \mathrm{mg} / \mathrm{L}$ anethol and $1.48 \mathrm{mg} / \mathrm{L}$ ethyl nonanoate, Sigma-Aldrich, St. Louis, MO, USA). The SPME device (Supelco Inc., Bellefonte, PA, USA) coated with PDMS $(100 \mu \mathrm{m})$ fiber was first conditioned by inserting it into the gas chromatograph injector port at $250{ }^{\circ} \mathrm{C}$ for $1 \mathrm{~h}$. For sampling, the fiber was inserted into the headspace under stirring $(300 \mathrm{rpm})$ for $30 \mathrm{~min}$ at $60^{\circ} \mathrm{C}$. Subsequently, the SPME device was introduced into the injector port of the Agilent Technologies 7890B chromatograph system equipped with LECO Pegasus High Throughput TOFMS, and kept in the inlet for $3 \mathrm{~min}$. The SPME process was automated using the GERSTEL MultiPurpose Sampler (MPS). The tested components were separated on a Rtx-1ms capillary column (Crossbond 100\% dimethyl polysiloxane, $30 \mathrm{~m} \times 0.53 \mathrm{~mm} \times 0.5 \mu \mathrm{m}$ ). The detector was $250{ }^{\circ} \mathrm{C}$, and the column was heated using the following temperature program: $40{ }^{\circ} \mathrm{C}$ for $3 \mathrm{~min}$ at an increment of $8{ }^{\circ} \mathrm{C} / \mathrm{min}$ to $230^{\circ} \mathrm{C}$, then maintaining a constant temperature for 9 min. Carrier: Helium at $1.0 \mathrm{~mL} / \mathrm{min}$ constant flow. EIMS electron energy $70 \mathrm{eV}$; ion source temperature and connection parts: 
$250{ }^{\circ} \mathrm{C}$. The analyte transfer was performed in splitless mode; the MSD was set to scan mode from $\mathrm{m} / \mathrm{z}=40$ to $\mathrm{m} / \mathrm{z}=400$. Compounds were identified using mass spectral libraries and linear retention indices, calculated based on a series of n-alkanes from C6 to C30. The qualitative and quantitative identification of volatile substances (ethyl acetate, ethyl butanoate, isoamyl acetate, ethyl hexanoate, ethyl octanoate, 2-phenylethyl acetate, ethyl decanoate, ethyl dodecanoate, ethyl tetradecanoate, ethyl hexadecanoate, ethyl octadecanoate, 2-methyl-1-propanol, 2-methyl-1-butanol, 2,3-butanodiol, 1-hexanol, 3-methyl-1-butanol, 2-phenylethanol, 1-nonanol, 1-decanol, hexanoic acid, octanoic acid, n-decanoic acid, limonene, linalol oxide, linalool, $\alpha$-terpineol, citronellol, geraniol, $B$-damascenone, B-caryophyllene, humulene, caryophyllene oxide, decanal; Sigma-Aldrich) were based on a comparison of retention times and peak surface area reads from samples and standard chromatograms. Other detected components were determined semi-quantitatively $(\mu \mathrm{g} / \mathrm{L})$ by measuring the relative peak area of each identified compound according to the National Institute of Standards and Technology (NIST) database [25] in relation to that of the internal standard. Each of the tests were performed three times.

Organic acid analysis: High performance liquid chromatography was applied for the analysis of the organic acids and the sugar profile. An HPLC analysis was carried out on a Perkin-Elmer (USA) FLEXAR chromatograph with a UV-Vis detector. Malic, oxalic, succinic, lactic, citric and acetic acids (Sigma-Aldrich) were determined using the Rezex ROA-Organic Acid Aminex HPX-87H (300 mm, $18 \mathrm{~cm} \times 7.8 \mathrm{~mm})$. Samples were eluted isocratically at $40{ }^{\circ} \mathrm{C}$ with a mobile phase $\left(0.005 \mathrm{M} \mathrm{H}_{2} \mathrm{SO}_{4}\right)$ at a flow rate of $0.4 \mathrm{~mL} / \mathrm{min}$ [26].

Content and profile of sugars: The content of sugars was determined using the HPLC method. Analysis of the sugar profile was conducted with the Shimadzu (Kyoto, Japan) NEXERA XR apparatus with a RF-20A refractometric detector. The separation was conducted with an Asahipak NH2P-50 $4.6 \times 250 \mathrm{~mm}$ Shodex column (Showa Denko Europe, Munich, Germany) thermostated at $30^{\circ} \mathrm{C}$. The mobile phase consisted of an acetonitrile aqueous solution $(70 \%)$, and the isocratic elution program $(0.8 \mathrm{~mL} / \mathrm{min})$ lasted $16 \mathrm{~min}$.

Quantitative determinations were made with the use of standard curves prepared for the appropriate standards: glucose, maltose and glycerol. The tables of results only present the concentrations of sugars with amounts higher than the method's detection threshold.

Weight loss during fermentation, related to release of $\mathrm{CO}_{2}$, was measured by the RADWAG WPS $600 / C$ scale.

Free amino nitrogen (FAN) was measured using ninhydrin-based methods with the use of the absorbance measurement at $450 \mathrm{~nm}$ (Beckman DU-650 UV-Vis) according to the Analytica EBC [27] method 8.10_Free Amino Nitrogen in wort by Spectrophotometry (IM).

The International Bitterness Unit (IBU) was measured with the use of isooctane extraction of iso$\alpha$-acids from acidified samples. After extraction, the absorbance analysis was conducted (Beckman DU-650 UV-Vis) with the use of a 275-nm wavelength according to Analytica EBC method 8.8_Bitterness of wort, the determination of the bitter substances, mainly iso- $\alpha$-acids, in wort.

The color of the filtered beer was measured spectrophotometrically (Beckman DU-650 UV-Vis) at a wavelength of $570 \mathrm{~nm}$ according to Analytica EBC method 8.5_Colour of wort: Spectrophotometric Method (IM).

Ion concentration: Before analyzing metal ions, wort and beer samples were mineralized to achieve the complete decomposition of their organic substances. Next, $2 \mathrm{~mL}$ of each sample was added to mineralizing dishes, and $\mathrm{HNO}_{3}$ was poured over the samples $(65 \%, 3 \mathrm{~mL})$. The samples were wet mineralized in a Mars Express microwave oven (at a maximum temperature of $170{ }^{\circ} \mathrm{C}$, duration: $40 \mathrm{~min}$ ). After wet mineralization, the contents of the mineralization dishes were transferred in quantity to test tubes and supplemented with deionized water to reach $14 \mathrm{~mL}$. Magnesium, calcium and zinc ions were analyzed with the VARIAN 240FS spectrometer using an atom spectrometer absorption method with flame atomization (air/acetylene). The device uses the automatic sample dosing system SPIS-20. $\mathrm{Mg}^{2+}$ ion absorbency was determined at a wavelength of $202.6 \mathrm{~nm}, \mathrm{Ca}^{2+}-422.7 \mathrm{~nm}, \mathrm{Zn}^{2+}-213.9 \mathrm{~nm}$. A fast sequential mode was run for the determination during a single aspiration of a sample. 


\subsubsection{Statistical Analyzis}

The results are presented as the average of three or more independent experiments with the bars representing the standard deviation. The data were analyzed through a one-way analysis of variance (ANOVA). The significance in the difference for each parameter was analyzed separately, using Tukey's range test (Statistica v. 10, StatSoft Inc., Krakow, Poland).

\section{Results}

\subsection{Fermentation Performance}

Wort fermentation progress was monitored by measuring the carbon dioxide release $(\mathrm{g} / \mathrm{L})$ over the following days of the process: From the time of wort inoculation to the fourth day of the process, samples inoculated with $\mathrm{Lt}$ produced twice the amount of carbon dioxide compared to samples inoculated with Sc (Figure 1). This may have been caused by the higher adaptability of the Lt strain to the fermentation conditions. Furthermore, the rate of the Lt process was not affected by the hop variety. During Sc fermentation, differences between fermentation media were observed only on the sixth and seventh days of the process. The results are similar to those obtained by Domizio et al. [19], where the progress of the process was not affected by the IBU level either at 30 or 60 IBU. Bellut et al. [18] also observed the minor impact of a high IBU value on the L. fermentati KBI 12.1. The volume of $\mathrm{CO}_{2}$ released between days six and seven of the process for all samples began to stabilize. However, from day 10 to the end of the process, higher volumes of evolved $\mathrm{CO}_{2}$ were found in the Sc samples.

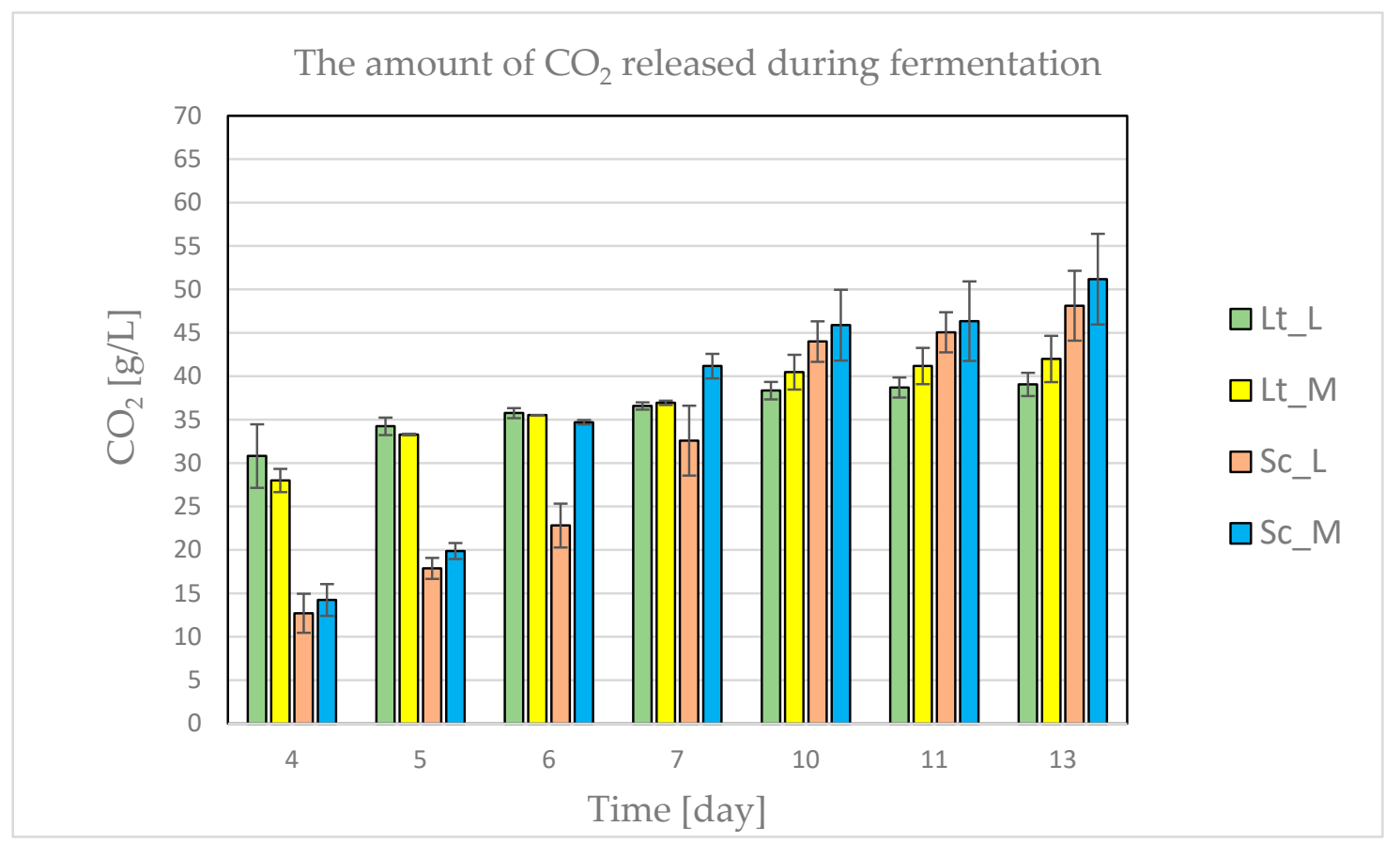

Figure 1. Carbon dioxide evolved during wort (hopped with Marynka (M) or Lubelski (L)) fermentation with L. thermotolerans $(\mathrm{Lt})$ or S. cerevisiae (Sc) yeast.

The high intensity of fermentation during the first days of the process is rarely observable in literature in the case of $L$. thermotolerans strains. However, the volume of $\mathrm{CO}_{2}$ at the later stages of the process presented a level similar to the results of Porter et al. [28], who analyzed L. thermotolerans (Concerto and Y940) and S. cerevisiae yeast fermentation kinetics. It was proven that, regardless of the fermentation medium used (synthetic grape juice or natural Muscat juice), the process rate was lower in the case of non-Sacharomyces monocultures. The differences in $\mathrm{CO}_{2}$ release reached approximately $27 \%$ less for Concerto and 36\% less for Y940. Similarly, Gobbi et al. [29], during the 24-day fermentation 
process of white grape, must have found a reduced rate of L. thermotolerans 101 culture fermentations compared to the pure culture of S. cerevisiae or S. cerevisiae with L. thermotolerans. According to Benito [22], Lachancea strains are characterized by relatively good fermentability; however, due to the longer transformation of sugars into alcohol, and the relatively high quantity of unfermented sugars left in the final product, the yeasts debuted in fermentations mixed with S. cerevisiae. Such combinations solve the above-mentioned issues and allow for considerably faster and more effective alcohol beverage production. Studies conducted by Balikci et al. [30] confirmed that the fastest reduction (from nine to seven days) of the original gravity was led by S. cerevisiae, as well as by the mixed $S$. cerevisiae and $L$. thermotolerans cultures in different variants against a single L. thermotolerans or variants initially inoculated with $L$. thermotolerans, followed by S. cerevisiae. Following analyses of various non-Saccharomyces yeasts, Plessis et al. [31] found two L. thermotolerans strains with fermentation capacities comparable to $S$. cerevisiae. This could be an indication of the reason why $L$. thermotolerans-as with $T$. delbrueckii-are selected from their species for commercial mixed cultures with S. cerevisiae. Interesting data were acquired by Comitini et al. [32] in the comparison of 34 non-Saccharomyces strains to some selected $S$. cerevisiae strains: he demonstrated that the mean daily $\mathrm{CO}_{2}$ produced by L. thermotolerans ranged from $0.03 \mathrm{~g} / \mathrm{L}$ to approximately $1.5 \mathrm{~g} / \mathrm{L}$, depending on the strain, while in the case of S. cerevisiae, the range would start at 1.3 and exceed $2.5 \mathrm{~g} / \mathrm{L}$. In the Canonico et al. [17] study, the total $\mathrm{CO}_{2}$ released after 20 days of fermentation conducted by different strains of $L$. thermotolerans also varied (between 20 and $39 \mathrm{~g} / \mathrm{L}$ ) in comparison with $46 \mathrm{~g} / \mathrm{L}$ evolved from wort by S. cerevisiae. This proves that, when comparing fermentation kinetics between S. cerevisiae and L. thermotolerans, the key role is a specific strain. In studies by Benito et al. [33], process kinetics were presented as having the capacity to utilize glucose and fructose from a fermentation medium over time. In this case, differences in the duration of the process ranged from 8 to 16 days, depending on the application of pure S. cerevisiae or a combination of L. thermotolerans and S. pombe strains.

\subsection{Beer}

After 14 days of fermentation, the alcohol content in the beers ranged from $4.26 \%$ to $5.37 \%(\mathrm{v} / \mathrm{v})$, while the real extract ranged from $3.92 \%$ to $5.46 \%(\mathrm{w} / \mathrm{w})$ (Table 2). The highest volume of ethanol was determined in beers produced with the use of Sc yeast: $5.37 \%$ in beer made with Lubelski hop and $5.22 \%$ in beer with Marynka. The percentage of ethanol content in beers fermented using Lt was significantly lower (4.3-4.25\%), irrespective of the type of hops used. This is reflected in the real extract content; its highest value was found in Lt samples, in contrast with the lowest ADF found in the strain $(67 \%)$. This may indicate a lower capacity for alcohol production by the analyzed strain when compared to Sc yeast. Holt et al. [16] tested the fermentation efficiency among 23 non-Saccharomyces yeast strains. Z. florentina and L. thermotolerans were the most effective at producing $4 \%$ and $2.6 \% \mathrm{v} / \mathrm{v}$ alcohol, respectively. The average alcohol content for all non-Saccharomyces yeast strains was $1.4 \% \mathrm{v} / \mathrm{v}$.

Table 2. Physicochemical parameters of beers depending on the strains and hop variety.

\begin{tabular}{|c|c|c|c|c|c|}
\hline & \multicolumn{2}{|c|}{ L. thermotolerans MN477031 } & \multicolumn{2}{|c|}{ S. cerevisiae Safbrew T-58 } & \multirow{2}{*}{ Sig. ${ }^{1}$} \\
\hline & Lubelski & Marynka & Lubelski & Marynka & \\
\hline Ethanol (\% v/v) & $4.3 \pm 0.02^{a}$ & $4.25 \pm 0.17^{\mathrm{a}}$ & $5.37 \pm 0.08^{b}$ & $5.22 \pm 0.16^{\mathrm{b}}$ & $* * *$ \\
\hline Real extract $(\% \mathrm{w} / \mathrm{w})$ & $5.46 \pm 0.017^{\mathrm{a}}$ & $5.41 \pm 0.010^{\mathrm{a}}$ & $4.03 \pm 0.035^{b}$ & $3.92 \pm 0.028^{c}$ & $* * *$ \\
\hline Apparent Degree of Fermentation (\%) & $67.38 \pm 0.1^{\mathrm{a}}$ & $67.31 \pm 1.2^{\mathrm{a}}$ & $82.83 \pm 0.28^{b}$ & $82.83 \pm 0.69^{b}$ & $* * *$ \\
\hline pH & $4.43 \pm 0.1^{\mathrm{a}}$ & $4.39 \pm 0.09^{a}$ & $4.72 \pm 0.08^{b}$ & $4.67 \pm 0.11^{b}$ & ** \\
\hline Color (EBC) & $8.0 \pm 0.91^{a}$ & $6.9 \pm 0.36^{\mathrm{a}}$ & $14.0 \pm 0.36^{b}$ & $7.5 \pm 0.12^{\mathrm{a}}$ & $* * *$ \\
\hline Glycerol (g/L) & $8.61 \pm 2.33^{a}$ & $9.29 \pm 2.37^{\mathrm{a}}$ & $4.72 \pm 1.14^{b}$ & $4.48 \pm 1.25^{b}$ & $* *$ \\
\hline FAN $(\mathrm{mg} / \mathrm{L})$ & $56.6 \pm 9.7$ & $65.9 \pm 6.5$ & $41.32 \pm 14.1$ & $53.38 \pm 2.8$ & ns \\
\hline
\end{tabular}

\footnotetext{
${ }^{1}$ Sig.: significance; ${ }^{* *}$ and ${ }^{* * *}$ display the significance at $1 \%$ and $0.5 \%$ by least significant difference; $n$ s: not significant.
} Values with different superscript roman letters $(\mathrm{a}-\mathrm{c})$ in the same row are significantly different according to the Tukey's range test $(p<0.05)$. 
These findings are consistent with results of other authors, starting with Kapsopoulou et al. [34], who were among the first to observe the dependencies, achieving an ethanol concentration at $7.58 \%$ $(\mathrm{v} / \mathrm{v})$ and $9.6 \%(\mathrm{v} / \mathrm{v})$ in wines as a result of fermenting L. thermotolerans and S. cerevisiae. Subsequent research $[28,35]$ confirmed this thesis, demonstrating increasing differences between $L$. thermotolerans and S. cerevisiae. According to the works, L. thermotolerans generated $8.3 \%(\mathrm{v} / \mathrm{v})$ and $8.9 \%(\mathrm{v} / \mathrm{v})$ of alcohol content against $11.1 \%(\mathrm{v} / \mathrm{v})$ and $12.3 \%(\mathrm{v} / \mathrm{v})$ of ethanol in the case of $S$. cerevisiae, which is similar to the findings of Comitini et al. [32] which were 4.58-7.96\% in comparison to $10.78-12.62 \%$, respectively. A lower alcohol production capacity demonstrated by L. thermotolerans strains as compared to $S$. cerevisiae strains does not signify the incapability of the yeast to biosynthesize increased volumes of the compound. By providing adequate conditions during the process, several authors succeeded in exceeding the $10 \%(\mathrm{v} / \mathrm{v})$. Du Plessis et al. [31] obtained 10.35\% (v/v), Gobbi et al. [29] obtained $10.46 \%(\mathrm{v} / \mathrm{v})$, Hranilovic et al. [11] obtained 10.6\% (v/v) and Balikci et al. [30] obtained 10.91\% (v/v) of ethanol. Nevertheless, it should be noted that, in the control samples (S. cerevisiae) of the above, the alcohol content was at least equal or higher. From the point of view of using L. thermotolerans in the brewing industry, resistance to a high concentration of alcohol is not the key criterion. Their potential for beer production was demonstrated by Domizio et al. [19]. In the process of fermenting wort and applying L. thermotolerans when compared to S. cerevisiae strains, the final alcohol content obtained in the test was only marginally lower (from $6 \%$ to $12 \%$ ) than in the strains used in the brewing industry. Canonico et al. [17] noted higher differences in ethanol concentrations between pure cultures of tested strains (ca. 22\%), while in the case of mixed fermentations, the obtained results were not significantly different. It is reasonable to assume that the lower capacity for transforming sugars to ethanol—demonstrated by L. thermotolerans—may be a positive factor when producing fermented beverages such as beer or sparkling or sweet wine with reduced alcohol content $[33,36,37]$. Furthermore, in beers produced with $L$. thermotolerans strains, a higher content of real extract was observed, which is justified by the lower ethanol content produced in the process. This may indicate that the available sugars are used to a lower degree by yeasts in ethanol biosynthesis, and that sugars can be used to generate higher amounts of other compounds (e.g., glycerol—a beer extract component).

\subsection{Sugars and Organic Acids}

Before fermentation, worts were characterized by similar levels of maltose (of approximately $85 \mathrm{~g} / \mathrm{L})$ and glucose $(13 \mathrm{~g} / \mathrm{L})$ (Table 1). Following the fermentation process, the observation was made that the Lt strain had fully consumed the glucose when compared to Sc at 0.040 and $0.036 \mathrm{~g} / \mathrm{L}$. In the case of maltose, its consumption was similar and-solely in the case of Sc beer hopped with the Marynka variation-slightly more maltose was left. This observation is reflected in the results of Domizio et al. [19], where L. thermotolerans and S. cerevisiae strains demonstrated similar maltose fermentation capacities, obtaining approximately 93-94\% of maltose consumption. Callejo et al. [38] proved a low maltose fermentation capacity by the L. thermotolerans $\mathrm{kt} 421$ strain compared to the strong fermentation by the S. cerevisiae 7VA strain. Interesting results were obtained by Canonico et al. [13]: among the 28 non-Saccharomyces stains (T. delbrueckii), only eight fermented maltose, whereas all of them had the ability to ferment glucose and sucrose. None of the strains showed comparable fermentation parameters to $S$. cerevisiae US-05, so they are suitable for the production of low-alcohol beers. One of the strains (T. delbrueckii DiSVA 254) which had the highest fermentation rate and $\mathrm{CO}_{2}$ production was used for further tests both as a pure culture and mixed with S. cerevisiae US-05. However, when analyzing the fermentation capacities of strains, the observations of Porter et al. [28] should also be taken into consideration. These indicated that the capacity was not only strain-dependent but also dependent on the fermentation medium. In synthetic grape juice, after the fermentation of S. cerevisiae, approximately $1 \mathrm{~g} / \mathrm{L}$ of glucose and approximately $2.5 \mathrm{~g} / \mathrm{L}$ of fructose were left compared to the same Muscat grape fermentation process, where neither glucose nor fructose were detected after the process. In the same study, from 10 to $45 \mathrm{~g} / \mathrm{L}$ of glucose and approximately 37 to $57 \mathrm{~g} / \mathrm{L}$ of fructose was left after synthetic juice fermentation, depending on the $L$. thermotolerans strain. Nevertheless, from 7 to $12 \mathrm{~g} / \mathrm{L}$ of glucose 
and 22-28 g/L of fructose was left after Muscat juice fermentation. Significantly lower levels of residual sugars were reported by Gobbi et al. [29], with S. cerevisiae at approximately $6 \mathrm{~g} / \mathrm{L}$ and L. thermotolerans at $55 \mathrm{~g} / \mathrm{L}$ after fermentation. In the case of the research work by Balikci et al. [30], a comparison of wines produced by $S$. cerevisiae and L. thermotolerans, led to the conclusion that $S$. cerevisiae yeasts demonstrated higher consumption of both glucose and fructose, remaining in wine at approximately 0.8 and $1.3 \mathrm{~g} / \mathrm{L}$, respectively, which is contrary to the higher content of these compounds in pure L. thermotolerans wine ( 2.3 and $4 \mathrm{~g} / \mathrm{L}$, respectively). Research carried out by Canonico et al. [17] also proved the lower fermentation ability of non-Saccharomyces yeast strains. The final gravity of beer produced by pure L. thermotolerans was higher (1.023) than that of S. cerevisiae (1.01).

No lactic, oxalic, acetic, citric, malic or succinic acids were found in the worts. An insignificant difference in the biosynthesis of organic acids was found in the finished beer (Table 3). A small concentration of lactic acid in the analyzed strain contradicts tests on other L. thermotolerans strains, which evidenced their higher levels. Domizio et al. [19] even described the L. thermotolerans 101 strain as a micro-organism representing a good alternative for sour beer production. The absence of a similar observation prevents the boarder application of the MN477031 strain in brewing across different styles of beer. Furthermore, only marginal differences in the $\mathrm{pH}$ of Lt and Sc beers signify the large potential of the analyzed strain.

Table 3. Concentration of glucose, maltose and organic acids in beers hopped with Marynka (M) or Lubelski (L) hop pellets fermented by L. thermotolerans $(\mathrm{Lt})$ or S. cerevisiae (Sc).

\begin{tabular}{ccccccccc}
\hline & Glucose & Maltose & Oxalic Acid & Acetic Acid & Citric Acid & Malic Acid $\begin{array}{c}\text { Succinic } \\
\text { Acid }\end{array}$ & $\begin{array}{c}\text { Lactic } \\
\text { Acid }\end{array}$ \\
\cline { 2 - 8 } & & \multicolumn{7}{c}{ g/L } \\
\hline Lt_L & $0.00 \pm 0.00^{\mathrm{a}}$ & $2.786 \pm 1.99^{\mathrm{a}}$ & $0.082 \pm 0.03$ & $0.160 \pm 0.03$ & $0.000 \pm 0.00$ & $0.030 \pm 0.01$ & $0.170 \pm 0.1$ & $0.01 \pm 0.00$ \\
Lt_M & $0.00 \pm 0.00^{\mathrm{a}}$ & $2.811 \pm 2.74^{\mathrm{a}}$ & $0.075 \pm 0.02$ & $0.174 \pm 0.13$ & $0.003 \pm 0.00$ & $0.052 \pm 0.02$ & $0.275 \pm 0.08$ & $0.06 \pm 0.07$ \\
Sc_L & $0.039 \pm 0.02^{\mathrm{b}}$ & $3.628 \pm 1.17^{\mathrm{a}}$ & $0.031 \pm 0.01$ & $0.390 \pm 0.04$ & $0.116 \pm 0.00$ & $0.039 \pm 0.01$ & $0.324 \pm 0.04$ & $0.00 \pm 0.00$ \\
Sc_M & $0.036 \pm 0.01^{\mathrm{c}}$ & $4.034 \pm 0.04^{\mathrm{b}}$ & $0.039 \pm 0.04$ & $0.232 \pm 0.18$ & $0.045 \pm 0.00$ & $0.025 \pm 0.01$ & $0.233 \pm 0.2$ & $0.00 \pm 0.00$ \\
Sig. ${ }^{*}$ & $* *$ & $*$ & ns & ns & ns & ns & ns \\
\hline
\end{tabular}

${ }^{1}$ Sig.: significance; ${ }^{*}$ and ${ }^{* *}$ display the significance at $5 \%$ and $1 \%$ by least significant difference; ns: not significant. Values with different superscript roman letters $(\mathrm{a}-\mathrm{c})$ in the same column are significantly different according to the Tukey's range test $(p<0.05)$.

\subsection{Glycerol}

No glycerol content was observed in the worts, while its concentration in the finished product was reported at approximately $4.5 \mathrm{~g} / \mathrm{L}$ for Sc, and approximately $9 \mathrm{~g} / \mathrm{L}$ for Lt (Table 2). In many studies, a similar trend of $L$. thermotolerans producing an increased amount of glycerol to reach approximately $8.0 \mathrm{~g} / \mathrm{L}$ was observed [11]. A percentage increase in the volume of the metabolite after 21 days of the fermentation was estimated to range from $65 \%$ to $75 \%$ [19]. Similar to the case of ethanol in mixed fermentations, glycerine concentrations are dependent on the moment of introducing the S. cerevisiae culture. These differences may reach up to $1.12 \mathrm{~g} / \mathrm{L}$. The final glycerol content is also influenced by the temperature. Fermentation at $30^{\circ} \mathrm{C}$ results in an increase in the glycerol produced in the process when compared to fermentation at $20^{\circ} \mathrm{C}$ [22]. Similarly, tests by Shekhawat et al. [39] proved that increased aeration during fermentation, both of pure L. thermotolerans cultures as well as those mixed with $S$. cerevisiae, leads to increased glycerol production with a simultaneous drop in ethanol efficiency. This was also seen and reflected in our study in the increased real extract in the case of Lt (Table 2), which includes glycerol [40]. In the reference fermentations (Sc), the amount of glycerol obtained was very similar to the control culture of Kapsopoulou et al. [41], which was S. cerevisiae.

\subsection{FAN}

Nitrogen compounds play an important role in the production of alcoholic beverages, mainly through their assimilation or metabolism by yeast cells during ethanol fermentation. In the brewing industry, they are very often referred to as FAN (free amino nitrogen) and contain individual alpha 
amino acids, ammonia and small peptides. In the wine industry, together with ammonium salts they are called YAN (yeast assimilable nitrogen). They can be also referred to as PAN (primary amino nitrogen), total usable nitrogen or usable nitrogen [42-44]. The FAN content in worts results from the barley malting process [45], mashing temperature profile [46,47] and content of nitrogen compounds in barley. Tests by Psota et al. [48] demonstrated that the FAN content in sweet wort and grains is largely dependent on the year of barley growing $(20 \%)$, the place of its growing $(14 \%)$ and its variety $(13 \%)$. Literature offers different recommended FAN levels for brewing wort [43]. In the case of Lt and Sc fermented samples, the obtained 130 to $140 \mathrm{mg} / \mathrm{L}$ is consistent with the minimum recommendations by Stewart et al. [49] and Butzke [50] for worts with 10-12 ${ }^{\circ} \mathrm{P}$ extract. What is important for this paper is that these requirements [43] have been met both for the brewer's and wine yeasts (Table 2). The lack of FAN in wort could cause slowed fermentation and poorer diacetyl reduction. In addition, FAN deficits are often accompanied by deficits of other nutrients and-in such cases-the deficit of absorbed nitrogen cannot be compensated by mineral or lipid supplementation [42]. On the other hand, an excessive level of FAN is not recommended, either. The Brewers Association recommends maintaining FAN at the necessary, minimum level [51]. During the fermentation process, a large amount of FAN is used by yeasts for building protein - supporting biomass growth. In addition, it is partially used for creating volatile compounds, including higher alcohols, esters, diacetyl and $\mathrm{H}_{2} \mathrm{~S}$ [52]. FAN content in ready beer is dependent on many factors and its value may widely vary. Its levels found in beers produced using Sc and Lt yeasts did not show any statistically significant difference in terms of the variety of hops used. These oscillated around $41-53 \mathrm{mg} / \mathrm{L}(\mathrm{Sc})$ and $57-66 \mathrm{mg} / \mathrm{L}(\mathrm{Lt})$, which is similar to the findings of Jaskula-Goris et al. [53] in the case of the lowest value for fresh beer $58.8 \mathrm{mg} / \mathrm{L}$, and is significantly different from its highest concentration of $124.1 \mathrm{mg} / \mathrm{L}$. In tests performed by Bellut et al. [18], S. cerevisiae demonstrated the capacity to utilize approximately $60 \%$ of FAN against the $65 \%$ recorded in this research. On the other hand, the analyzed L. fermentati KBI 12.1 strain used FAN at no more than 30\% when compared to $55 \%$ for the Lt strain reported in our research. An excessive volume of FAN in beer is not recommended, largely owing to its potential to contribute to the generation of undesirable products (e.g., Mailard's reactions or Strecker degradation [53]), and thus potentially reducing beer stability [54].

\subsection{Esters, Alcohols and Other Volatile Compounds}

One of the key objectives for using non-Saccharomyces yeast in brewing is the modification of the sensory profile of beverages. Generally, such methods are recognized as the concept of bioflavoring [52]. The main compounds that influence the aroma of alcoholic beverages are esters, higher alcohols, terpenes, acids and so on [55]. In addition, ethanol is also an important factor in the organoleptic perception of beer. As a result of the fermentation, many new volatiles have appeared in beer, and some of them have significantly increased their concentration (Table 4). Furthermore, the analysis of volatile compounds leads to the observation that beers produced using Lt demonstrated a significant difference from the beer brewed with Sc. In order to prove the differences in the concentrations of volatile compounds, a decision was made to first prove that the differences were occurring at the same time, irrespective of the variety of hops used. In case of ester compounds in beer, Lt application significantly reduced the concentration of almost all the analyzed esters (Table 4). The exceptions were ethyl 2-methyloctanoate (higher concentration in Lt) and ethyl acetate, whose concentration in the Sc_M sample was comparable to that of Lt. The obtained results are in agreement with other studies (e.g., Balikci et al. [30]), proving the lower amount of ester in L. thermotolerans products. Canonico et al. [17] obtained a higher concentration of ethyl butyrate and ethyl acetate in beer produced by L. thermotolerans and, similar to the present study, a lower concentration of other measured esters (2-phenylethyl acetate, ethyl hexadecanoate and isoamyl acetate). In the case of several ester compounds, the variety of hops used in the process was also important for Sc beers (e.g., in case of ethyl 9-decenoate). The difference in ester concentration between produced beers is very important to overall sensory expression. This is mainly due to their low thresholds and positive effect on the 
aroma of beers, introducing floral and fruity notes. Higher glucose and fructose content in wort leads to higher concentrations of ester than in maltose-rich worts $[38,56]$. In Lt-fermented beers, the content of alcohols 3-ethoxy-1-propanol, 1-nonanol and 1-decanol were significantly higher than in Sc, whereas the 2-methyl-1-propanol, 2-methyl-1-butanol, 2,3-butanediol, 3-methyl-1-butanol and 1-heptanol were formed in lower concentrations compared to in the reference sample. In the study by Callejlo et al. [38], similar trends were observed for 2-methyl-1-butanol and 3-methyl-1-butanol. Gobbi et al. [29] and Canonico et al. [17] also reported a significant reduction of 2-methyl-1-propanol and 3-methyl-1-butanol levels when producing wine or beer with a pure $L$. thermotolerans strain as compared with S. cerevisiae. In research by Balikci et al. [30], a sample obtained by a pure culture of $L$. thermotolerans was also characterized by a lower concentration of 2-methyl-1-propanol, 2-methyl-1-butanol and 3-methyl-1-butanol and a more than twofold increase in the concentration of N-propanol. For most of the volatile organic acids detected, smaller amounts were also found in beers obtained with the L. thermotolerans yeasts. In terms of acids, only in hexanoic and octanoic acid was the lower amount statistically significant. This may explain why the samples contained smaller amounts of esters for which the acids were precursors [57,58]. No significant differences dependent on application of Lt were observed in cases of phenols.

Table 4. Volatile compounds in beer brewed with Marynka (M) or Lubelski (L) hop pellets, fermented by L. thermotolerans (Lt) or S. cerevisiae (Sc).

\begin{tabular}{|c|c|c|c|c|c|c|}
\hline \multirow{2}{*}{ Compound $[\mu \mathrm{g} / \mathrm{L}]$} & \multirow{2}{*}{ LRI $^{2}$} & \multicolumn{2}{|c|}{ Lt } & \multicolumn{2}{|c|}{ Sc } & \multirow{2}{*}{ Sig. ${ }^{1}$} \\
\hline & & L & $\mathbf{M}$ & L & $\mathbf{M}$ & \\
\hline \multicolumn{7}{|c|}{ Esters } \\
\hline Ethyl Acetate & 614 & $4302 \mathrm{a}$ & $3200 \mathrm{a}$ & $8525 \mathrm{~b}$ & $3116 a$ & $* * *$ \\
\hline n-Propyl acetate ${ }^{3}$ & 694 & $0 \mathrm{~b}$ & $0 \mathrm{~b}$ & $76.6 \mathrm{~b}$ & $21.5 \mathrm{a}$ & $* *$ \\
\hline Ethyl butanoate & 789 & $7.4 \mathrm{a}$ & $8.1 \mathrm{a}$ & $34.8 \mathrm{~b}$ & $36.2 \mathrm{~b}$ & $* * *$ \\
\hline Isoamyl acetate & 872 & $43.0 \mathrm{a}$ & $65.0 \mathrm{~b}$ & $271.7 \mathrm{c}$ & $293.8 \mathrm{c}$ & $* * *$ \\
\hline Ethyl hexanoate & 986 & $4.1 \mathrm{a}$ & $8.6 \mathrm{a}$ & $116.4 \mathrm{~b}$ & $91.1 \mathrm{~b}$ & $* * *$ \\
\hline Ethyl octanoate & 1180 & $10.4 \mathrm{a}$ & $11.8 \mathrm{a}$ & $1776.6 \mathrm{~b}$ & $2480.4 \mathrm{~b}$ & $* * *$ \\
\hline Ethyl 2-methyloctanoate ${ }^{3}$ & 1209 & $69.7 \mathrm{a}$ & $43.2 \mathrm{a}$ & $10.7 \mathrm{~b}$ & $29.2 \mathrm{~b}$ & $* * *$ \\
\hline 2-Phenylethyl acetate & 1228 & $55.8 \mathrm{a}$ & $57.8 \mathrm{a}$ & $777.14 b$ & $2863.32 \mathrm{c}$ & $* * *$ \\
\hline Ethyl 9-decenoate ${ }^{3}$ & 1389 & $0.6 \mathrm{a}$ & $0.4 \mathrm{a}$ & $38.6 \mathrm{~b}$ & $105.9 \mathrm{c}$ & $* * *$ \\
\hline Ethyl decanoate & 1397 & $4.4 \mathrm{a}$ & $2.7 \mathrm{a}$ & $306.2 \mathrm{~b}$ & $392.9 \mathrm{~b}$ & $* * *$ \\
\hline Isobutyl decanoate $^{3}$ & 1546 & $0 \mathrm{a}$ & $0 \mathrm{a}$ & $0.24 \mathrm{~b}$ & $0.60 \mathrm{c}$ & $* * *$ \\
\hline Ethyl dodecanoate & 1581 & $0.8 \mathrm{a}$ & $0.4 \mathrm{a}$ & $48.3 \mathrm{~b}$ & $38.1 b$ & $* * *$ \\
\hline Benzyl Benzoate 3 & 1750 & 1.05 & 0.45 & 0.38 & 0.14 & ns \\
\hline Ethyl tetradecanoate & 1790 & $1.1 \mathrm{a}$ & $0.4 \mathrm{a}$ & $4.8 \mathrm{~b}$ & $3.2 \mathrm{~b}$ & $* * *$ \\
\hline Ethyl pentadecanoate 3 & 1880 & 0 & 0 & 0.6 & 0.8 & ns \\
\hline Ethyl 9-hexadecenoate $^{3}$ & 1977 & $1.04 \mathrm{ab}$ & $0.55 \mathrm{~b}$ & $1.35 \mathrm{a}$ & $1.08 \mathrm{ab}$ & $* * *$ \\
\hline Ethyl hexadecanoate & 1990 & $3.4 \mathrm{a}$ & $1.5 \mathrm{a}$ & $10.9 \mathrm{~b}$ & $9.8 \mathrm{~b}$ & $* * *$ \\
\hline Ethyl octadecanoate & 2189 & 0.8 & 0.1 & 0.7 & 0.6 & ns \\
\hline \multicolumn{7}{|c|}{ Alcohols } \\
\hline 2-Methyl-1-propanol & 617 & $123.2 \mathrm{a}$ & $113.7 \mathrm{a}$ & $343.8 \mathrm{~b}$ & $441.4 \mathrm{~b}$ & $* * *$ \\
\hline 3-Methyl-1-butanol & 723 & 8856 a & $7379 \mathrm{a}$ & $11105 \mathrm{~b}$ & $17997 \mathrm{c}$ & $* * *$ \\
\hline 2-Methyl-1-butanol & 740 & $2413 \mathrm{a}$ & $1792 \mathrm{a}$ & $3888 \mathrm{~b}$ & $6544 \mathrm{c}$ & $* * *$ \\
\hline 2,3-Butanediol & 768 & $174 \mathrm{a}$ & $136 \mathrm{a}$ & $585 \mathrm{~b}$ & 1446 c & $* * *$ \\
\hline 3-Ethoxy-1-propanol ${ }^{3}$ & 862 & $276.5 \mathrm{a}$ & $91.7 \mathrm{a}$ & $0 \mathrm{~b}$ & $0 \mathrm{~b}$ & $* * *$ \\
\hline 1-Hexanol & 865 & $32.5 \mathrm{a}$ & $27.9 \mathrm{ac}$ & $26.9 \mathrm{ac}$ & $23.4 \mathrm{c}$ & * \\
\hline 1-Heptanol ${ }^{3}$ & 954 & $6.6 \mathrm{a}$ & $5.5 \mathrm{a}$ & $12.3 \mathrm{~b}$ & $12.8 \mathrm{~b}$ & $* *$ \\
\hline 2-Ethyl-1-hexanol ${ }^{3}$ & 1020 & 37.8 & 31.7 & 23.6 & 24.9 & ns \\
\hline 2-Phenylethanol & 1084 & $2151 \mathrm{a}$ & $3807 \mathrm{~b}$ & $3892 \mathrm{~b}$ & 9196 c & $* * *$ \\
\hline 1-Nonanol & 1156 & $61.9 \mathrm{a}$ & $59.2 \mathrm{a}$ & $15.6 \mathrm{~b}$ & $16.2 \mathrm{~b}$ & $* *$ \\
\hline 2-Propyl-1-heptanol ${ }^{3}$ & 1203 & 16.3 & 15.8 & 11.3 & 10.9 & ns \\
\hline 2-[(2-Ethylhexyl)oxy]-ethanol ${ }^{3}$ & 1226 & 507 a & $487 \mathrm{ab}$ & $481 \mathrm{ab}$ & $311 \mathrm{~b}$ & $*$ \\
\hline 1-Decanol & 1272 & $465 \mathrm{a}$ & $467.8 \mathrm{a}$ & $320.5 \mathrm{~b}$ & $186.9 \mathrm{c}$ & $* * *$ \\
\hline 1-Undecanol & 1374 & 37.0 & 33.1 & 20.4 & 9.8 & ns \\
\hline 2-Dodecanol & 1417 & 4.8 & 4.5 & 1.3 & 1.4 & ns \\
\hline
\end{tabular}


Table 4. Cont.

\begin{tabular}{|c|c|c|c|c|c|c|}
\hline \multirow{2}{*}{ Compound $[\mu \mathrm{g} / \mathrm{L}]$} & \multirow{2}{*}{ LRI $^{2}$} & \multicolumn{2}{|c|}{ Lt } & \multicolumn{2}{|c|}{ Sc } & \multirow{2}{*}{ Sig. } \\
\hline & & L & $\mathbf{M}$ & $\mathbf{L}$ & $\mathbf{M}$ & \\
\hline \multicolumn{7}{|c|}{ Acids } \\
\hline 3-Methylbutanoic acid ${ }^{3}$ & 833 & 112.2 & 75.9 & 116.2 & 139.6 & ns \\
\hline 2-Methylbutanoic acid ${ }^{3}$ & 858 & 16.9 & 0 & 31.5 & 21.8 & ns \\
\hline Hexanoic acid & 982 & $16.5 \mathrm{a}$ & $11.9 \mathrm{a}$ & $44.0 \mathrm{~b}$ & $79.9 \mathrm{~b}$ & $* * *$ \\
\hline Octanoic acid & 1160 & 297 a & $293 \mathrm{a}$ & $1724 b$ & $2874 \mathrm{c}$ & $* * *$ \\
\hline 9-Decenoic acid ${ }^{3}$ & 1358 & $11.0 \mathrm{a}$ & $4.8 \mathrm{~b}$ & $12.3 \mathrm{a}$ & $18.8 \mathrm{c}$ & $*$ \\
\hline n-Decanoic acid & 1368 & $69.3 \mathrm{a}$ & $46.6 \mathrm{~b}$ & $72.9 \mathrm{a}$ & $126.5 \mathrm{c}$ & $* * *$ \\
\hline \multicolumn{7}{|c|}{ Phenols } \\
\hline 2-Methoxy-4-vinylphenol ${ }^{3}$ & 1324 & $1.49 \mathrm{a}$ & $1.08 \mathrm{~b}$ & $0.47 \mathrm{c}$ & $27.4 \mathrm{~d}$ & $* * *$ \\
\hline Butylated Hydroxytoluene ${ }^{3}$ & 1513 & $0.49 \mathrm{a}$ & $0.7 \mathrm{a}$ & $0.25 \mathrm{~b}$ & $\mathrm{n} / \mathrm{d}$ & $* * *$ \\
\hline \multicolumn{7}{|c|}{ Carbonyl compounds } \\
\hline Decanal & 1182 & $17.5 \mathrm{a}$ & $14.8 \mathrm{a}$ & $0 \mathrm{~b}$ & $0 \mathrm{~b}$ & $* * *$ \\
\hline 2-Dodecanol ${ }^{3}$ & 1417 & $4.75 \mathrm{a}$ & $4.55 \mathrm{a}$ & $1.26 \mathrm{~b}$ & $1.35 \mathrm{~b}$ & * \\
\hline \multicolumn{7}{|c|}{ Acetals } \\
\hline Diethyl acetal & 730 & $7178 \mathrm{a}$ & $6561 \mathrm{a}$ & $2874 \mathrm{~b}$ & $2750 \mathrm{~b}$ & $*$ \\
\hline 1-Ethoxy-1-propoxyethane ${ }^{3}$ & 755 & $24.9 \mathrm{a}$ & $18.3 \mathrm{a}$ & $13 \mathrm{a}$ & $0 \mathrm{~b}$ & * \\
\hline 1-Butoxy-1-ethoxyethane ${ }^{3}$ & 875 & $21.7 \mathrm{a}$ & $19.8 \mathrm{a}$ & $14.9 \mathrm{a}$ & $39.4 \mathrm{~b}$ & * \\
\hline 1-(1-Ethoxyethoxy)pentane & 977 & 133.2 & 123.3 & 112.7 & 140.4 & ns \\
\hline \multicolumn{7}{|c|}{ Other compounds } \\
\hline Benzothiazole $^{3}$ & 1186 & 78.4 & 156.9 & 134.7 & 88.2 & ns \\
\hline Octane, $1,1^{\prime}$-oxybis- ${ }^{3}$ & 1657 & 3.93 & 4.36 & 2.34 & 4.38 & ns \\
\hline
\end{tabular}

${ }^{1}$ Sig.: significance; ${ }^{*}, * *$, and ${ }^{* *}$ display the significance at $5 \%, 1 \%$, and $0.5 \%$ by least significant difference; ns: not significant. Values with different superscript roman letters $(a-d)$ in the same row are significantly different according to the Tukey's range test $(p<0.05) ;{ }^{2}$ LRI-Linear Retention Index; ${ }^{3}$ determined semi-quantitatively by measuring the relative peak area of each identified compound, according to the NIST [25] database, in relation to that of the internal standard.

Decanal (sweet, waxy, orange, citrus peel aroma) and 2-dodecanol (floral aroma)-representing carbonyl compounds-were found at a significantly higher quantity in Lt when compared to its presence in Sc. It has been proven in other research that it is not only the selection of the strain and fermentation medium that have a significant impact on the volatiles profile, but also the ratio of individual microorganisms in the mixed culture. Morales et al. [35] presented the content of volatile compounds depending on the strain dominant during inoculation; in this manner, the dominant L. thermotolerans culture in the environment triggered an increase in alcohol levels, while S. cerevisiae caused a linear reduction in acetals, acids and ethyl esters accompanied by its increased share during inoculation. Comitini et al. [32] demonstrated that mixed cultures of L. thermotolerans intensified the production of 2-phenylethanol and reduction in octanoic acid. Benito et al. [33] determined an increased level of higher alcohols in samples engaging L. thermotolerans and S. cerevisiae when compared to $S$. pombe samples.

\subsection{Terpenes}

Terpenes are the main constituents of hops' essential oils and contribute to the singular sensory properties of beer. More than $90 \%$ of the hop oil volatilizes during the boiling period and the traces are found in the hopped wort [59]. Although $\beta$-myrcene, $\alpha$-humulene, $\beta$-caryophyllene and $\beta$-farnesene have been shown to be the main components of hop oil, the predominant components in finished beer are terpene alcohols, especially linalool and geraniol [60]. Different yeast species have different ability to release terpenes from the bound form ( $\beta$-glicosidase activity) and metabolize them to other terpenes [61]. However, there is not much information in the literature about such transformations of non-Saccharomyces yeasts, which significantly differ in metabolism from starter brewing cultures. Worts hopped with two different hops (Marynka, Lubelski) were characterized by a similar composition 
of terpenes, among which geraniol, humulene epoxide II, humulene, $\beta$-farnesene and patchulane dominated (Table 5). After fermentation, significant changes in the quantitative and qualitative composition of the terpenes were observed, with more of these compounds found in beers obtained with $L$. thermotolerans yeasts. Limonene, perillen, nerol and humulene were completely used in all samples, as well as perilla alcohol and caryophyllene oxide in samples fermented by S. cerevisiae. At the same time citronellol, $\beta$-damascenone and nerolidol were formed, terpenes were not detected in unfermented worts. In Lt beers, terpenes derived from hops-such as humulene epoxide II, geraniol and patchulane-predominated. To a lesser extent, those produced de novo (e.g., citronellol and linalool) were, in contrast to Sc beer dominated by citronellol, humulene epoxide II, patchulane and linalool. The above tendency is very important for the production of beers with a modified, specific aroma in which the presence of terpenes can be significantly more perceptible due to the smaller amounts of other aroma compounds such as esters and alcohols. In the research of Canonico et al. [17] on terpene concentrations in beer, the citronellol amount was significantly lower in beer produced by pure L. thermotolerans in comparison with beer fermented by pure S. cerevisiae or mixed with L. thermotolerans.

Table 5. Terpenes in hopped wort and beer brewed with Marynka (M) or Lubelski (L) hop pellets, fermented by L. thermotolerans (Lt) or S. cerevisiae (Sc).

\begin{tabular}{|c|c|c|c|c|c|c|c|c|}
\hline \multirow{2}{*}{ Compound $[\mu \mathrm{g} / \mathrm{L}]$} & \multirow{2}{*}{ LRI $^{2}$} & \multicolumn{2}{|c|}{ Wort } & \multicolumn{2}{|c|}{$\mathbf{L t}$} & \multicolumn{2}{|c|}{ Sc } & \multirow{2}{*}{ Sig. ${ }^{1}$} \\
\hline & & $\mathbf{L}$ & $\mathbf{M}$ & L & $\mathbf{M}$ & $\mathbf{L}$ & $\mathbf{M}$ & \\
\hline Limonene & 1027 & $0.08 \mathrm{ab}$ & $0.28 \mathrm{~b}$ & $0.00 \mathrm{a}$ & $0.00 \mathrm{a}$ & $0.00 \mathrm{a}$ & $0.00 \mathrm{a}$ & $* * *$ \\
\hline cis-Linalol oxide & 1066 & $0.34 \mathrm{ab}$ & $0.28 \mathrm{ab}$ & $0.42 \mathrm{~b}$ & $0.34 \mathrm{ab}$ & $0.41 \mathrm{~b}$ & $0.18 \mathrm{a}$ & * \\
\hline Linalool & 1092 & 1.21 & 0.80 & 0.98 & 0.80 & 1.15 & 0.44 & ns \\
\hline Perillen ${ }^{3}$ & 1101 & $0.31 \mathrm{~b}$ & $0.36 \mathrm{~b}$ & $0.00 \mathrm{a}$ & $0.00 \mathrm{a}$ & $0.00 \mathrm{a}$ & $0.00 \mathrm{a}$ & $* * *$ \\
\hline$\alpha$-Terpineol & 1171 & 0.84 & 0.69 & 0.70 & 0.68 & 0.46 & 0.65 & ns \\
\hline Citronellol & 1210 & $0.00 \mathrm{a}$ & $0.00 \mathrm{a}$ & $0.88 \mathrm{ab}$ & $2.22 \mathrm{c}$ & $1.23 \mathrm{bc}$ & $3.50 \mathrm{~d}$ & $* * *$ \\
\hline Nerol $^{3}$ & 1218 & $0.59 \mathrm{~b}$ & $1.06 \mathrm{c}$ & $0.00 \mathrm{a}$ & $0.00 \mathrm{a}$ & $0.00 \mathrm{a}$ & $0.00 \mathrm{a}$ & $* * *$ \\
\hline Geraniol & 1257 & $3.41 \mathrm{c}$ & $12.25 \mathrm{e}$ & $1.28 \mathrm{~b}$ & $4.34 \mathrm{~d}$ & $0.60 \mathrm{ab}$ & $0.34 \mathrm{a}$ & $* * *$ \\
\hline Perilla alcohol ${ }^{3}$ & 1295 & $0.74 \mathrm{c}$ & $0.41 \mathrm{~b}$ & $0.20 \mathrm{a}$ & $0.09 \mathrm{a}$ & $0.00 \mathrm{a}$ & $0.00 \mathrm{a}$ & $* * *$ \\
\hline$\beta$-Damascenone & 1384 & $0.00 \mathrm{a}$ & $0.00 \mathrm{a}$ & $0.18 \mathrm{~b}$ & $0.16 \mathrm{~b}$ & $0.48 \mathrm{~b}$ & $0.40 \mathrm{~b}$ & * \\
\hline$\beta$-Caryophyllene & 1414 & $1.06 \mathrm{bc}$ & $1.33 \mathrm{c}$ & $0.65 a b$ & $0.62 \mathrm{ab}$ & $0.66 \mathrm{ab}$ & $0.27 \mathrm{a}$ & $* * *$ \\
\hline Geranyl acetone ${ }^{3}$ & 1443 & $0.83 \mathrm{ab}$ & $1.09 \mathrm{~b}$ & $0.73 \mathrm{ab}$ & $0.54 \mathrm{a}$ & $0.65 \mathrm{ab}$ & $0.51 \mathrm{a}$ & $*$ \\
\hline Humulene & 1455 & $3.46 \mathrm{~b}$ & $3.61 \mathrm{~b}$ & $0.00 \mathrm{a}$ & $0.00 \mathrm{a}$ & $0.00 \mathrm{a}$ & $0.00 \mathrm{a}$ & $* * *$ \\
\hline$\beta$-Farnesene ${ }^{3}$ & 1462 & $2.43 \mathrm{~b}$ & $3.12 \mathrm{~b}$ & $0.70 \mathrm{a}$ & $0.76 \mathrm{a}$ & $0.57 \mathrm{a}$ & $0.54 \mathrm{a}$ & $* * *$ \\
\hline$\alpha$-Calacorene ${ }^{3}$ & 1540 & $0.06 \mathrm{a}$ & $0.08 \mathrm{ab}$ & $0.13 \mathrm{bc}$ & $0.14 \mathrm{c}$ & $0.18 \mathrm{c}$ & $0.13 \mathrm{bc}$ & $* * *$ \\
\hline Caryophyllene oxide & 1573 & $1.40 \mathrm{~b}$ & $1.85 \mathrm{c}$ & $0.19 \mathrm{a}$ & $0.20 \mathrm{a}$ & $0.00 \mathrm{a}$ & $0.00 \mathrm{a}$ & $* * *$ \\
\hline Nerolidol $^{3}$ & 1562 & $0.00 \mathrm{a}$ & $0.00 \mathrm{a}$ & $0.71 \mathrm{~b}$ & $0.63 \mathrm{~b}$ & $0.42 \mathrm{~b}$ & $0.41 \mathrm{~b}$ & $* * *$ \\
\hline Humulol $^{3}$ & 1600 & $0.70 \mathrm{~b}$ & $0.71 \mathrm{~b}$ & $0.44 \mathrm{a}$ & $0.31 \mathrm{a}$ & $0.47 \mathrm{a}$ & $0.31 \mathrm{a}$ & * \\
\hline Humulene epoxide II $^{3}$ & 1606 & $5.66 \mathrm{bc}$ & $6.50 \mathrm{c}$ & $3.66 \mathrm{ab}$ & $2.61 \mathrm{a}$ & $2.72 \mathrm{a}$ & $1.80 \mathrm{a}$ & $* * *$ \\
\hline Patchulane $^{3}$ & 1618 & $2.78 \mathrm{~b}$ & $2.91 \mathrm{~b}$ & $1.65 \mathrm{a}$ & $1.56 \mathrm{a}$ & $1.71 \mathrm{a}$ & $1.23 \mathrm{a}$ & $* * *$ \\
\hline Aromadendrene epoxide ${ }^{3}$ & 1623 & $1.21 \mathrm{~d}$ & $1.05 \mathrm{~cd}$ & $0.71 \mathrm{bc}$ & $0.53 \mathrm{~b}$ & $0.19 \mathrm{a}$ & $0.13 \mathrm{a}$ & $* * *$ \\
\hline$\alpha$-Muurolol ${ }^{3}$ & 1632 & $0.51 \mathrm{~b}$ & $0.60 \mathrm{~b}$ & $0.24 \mathrm{a}$ & $0.20 \mathrm{a}$ & $0.17 \mathrm{a}$ & $0.12 \mathrm{a}$ & $* * *$ \\
\hline$\tau$-Muurolol ${ }^{3}$ & 1646 & $1.69 \mathrm{~d}$ & $2.14 \mathrm{~d}$ & $0.89 c$ & $0.85 \mathrm{bc}$ & $0.34 \mathrm{ab}$ & $0.28 \mathrm{a}$ & $* * *$ \\
\hline
\end{tabular}

${ }^{1}$ Sig.: significance; ${ }^{*}$ and ${ }^{* * *}$ display the significance at $5 \%$ and $0.5 \%$ by least significant difference; $n$ s: not significant. Values with different superscript roman letters (a-d) in the same raw are significantly different according to the Tukey's range test $(p<0.05) ;{ }^{2}$ LRI-Linear Retention Index; ${ }^{3}$ determined semi-quantitatively by measuring the relative peak area of each identified compound, according to the NIST [25] database, in relation to that of the internal standard.

\subsection{Metal Ions}

An important factor affecting the fermentation process and beer quality is the ion composition of the worts. Some ions (e.g., $\mathrm{Mg}^{2+}$ and $\mathrm{Zn}^{2+}$ ) have a significant impact on the vitality of yeasts and support the progress of the fermentation process [62]. The content of trace quantities of the elements in raw materials and final products of the brewing industry should be under continuous control. 
The controlling amount of ions in raw materials and process operations impact the ion content in the wort significantly [63]. Brewing yeasts demonstrates a high demand for magnesium ions in the wort (ranging from 50 to $150 \mathrm{mg} / \mathrm{L}$ or more), which is rather uncommon for other metals [63]. A deficit of this element causes a number of complex and often subtle changes in yeast cells physiology $[63,64]$. In pitching worts, the content of magnesium reached nearly $200 \mathrm{mg} / \mathrm{L}$ (Table 6) and, for this reason, wort supplementation was not necessary in order to improve the fermentation process. Calcium was the next ion analyzed in the research. The optimum $\mathrm{Ca}^{2+}$ content for the proper growth of the yeasts and progress of the fermentation process was determined in the range of $30-60 \mathrm{mg} / \mathrm{L}$ of wort [63]. All the analyzed samples had the appropriate calcium content, consistent with the data presented in the literature. Zinc is required for the proper growth of yeasts and fermentation, although its content is not generally high. This element also contributes to the accumulation of sugars, and the optimum demand of yeast for zinc ranges from 0.1 to $1 \mathrm{mg} / \mathrm{L}$ of wort $[65,66]$. The analyzed samples were characterized by a higher content of the element. This must have been caused by the high zinc extraction from malt during mashing and mash filtration.

Table 6. The content of selected ions in wort brewed with Marynka (M) or Lubelski (L) hop pellets, and beer fermented by L. thermotolerans (Lt) or S. cerevisiae (Sc).

\begin{tabular}{|c|c|c|c|c|c|c|c|}
\hline & $\begin{array}{c}\mathrm{L} \\
\mathrm{mg} / \mathrm{L}\end{array}$ & $\underset{\mathrm{mg} / \mathrm{L}}{\mathrm{M}}$ & $\begin{array}{l}\text { Lt_L } \\
\text { mg/L }\end{array}$ & $\begin{array}{l}\text { Lt_M } \\
\text { mg/L }\end{array}$ & $\begin{array}{l}\text { Sc_L } \\
\mathrm{mg} / \mathrm{L}\end{array}$ & $\begin{array}{l}\text { Sc_M } \\
\mathrm{mg} / \mathrm{L}\end{array}$ & Sig. ${ }^{1}$ \\
\hline Ca 422.7 & 53.0 & 67.3 & $43.1 \pm 5.04$ & $62.8 \pm 26.3$ & $50.9 \pm 3.4$ & $42.6 \pm 2.25$ & ns \\
\hline Fe 248.3 & 10.0 & 12.1 & $9.9 \pm 0.23$ & $10.5 \pm 0.1$ & $10.3 \pm 0.69$ & $10.1 \pm 0.13$ & ns \\
\hline Zn 213.9 & 1.65 & 1.69 & $1.64 \pm 0.19$ & $1.72 \pm 0.9$ & $1.49 \pm 0.25$ & $1.09 \pm 0.13$ & ns \\
\hline Mg 202.6 & 197.9 & 199.7 & $147.21 \pm 17.46$ & $150.75 \pm 21.9$ & $168.82 \pm 13.3$ & $165.59 \pm 3.01$ & $\mathrm{~ns}$ \\
\hline
\end{tabular}

${ }^{1}$ Sig.: significance; ns: not significant. Values with different superscript roman letters $(a-b)$ in the same row are significantly different according to the Tukey's range test $(p<0.05)$.

\section{Conclusions}

This study examined the impact of the L. thermotolerans MN477031 strain on brewing production. The progress of the fermentation process was monitored for two types of worts. It was investigated that the MN477031 strain had a high adaptability to the fermentation conditions and produced more than $4 \% \mathrm{v} / \mathrm{v}$ ethanol from the $12 \% \mathrm{w} / \mathrm{w}$ wort, which is above average for non-Saccharomyces yeast strains. Furthermore, the aroma profile of beer was changed due to, for example, lower esters and volatile acids concertation compared to the Safbrew T-58 strain.

One of the key characteristics of the L. thermotolerans MN477031 strain was the low lactic acid production and only a minor impact on the reduction in $\mathrm{pH}$ of the beer, in comparison with the reference sample and known L. thermotolerans strains.

In addition, the following characteristics provide high potential for the application of the MN477031 strain in different beer styles: high maltose fermentation ability, resistance to higher IBU levels of a minimum up to 53, a similar requirement for FAN and metal ions in worts and higher glycerol productions in comparison to the Safbrew T-58 strain, which could improve the mouthfeel of the produced beers.

Author Contributions: Conceptualization, P.S. and M.Z.; methodology, M.Z. and P.S.; software, P.S.; validation, P.S. and M.Z.; formal analysis, P.S., M.Z. and A.P.; investigation, A.P. and S.B.; resources, M.Z.; data curation, P.S.; writing—original draft preparation, M.Z.; writing—review and editing, P.S. and M.Z.; visualization, P.S. and M.Z.; supervision, P.S. and M.Z.; project administration, A.P.; funding acquisition, M.Z. All authors have read and agreed to the published version of the manuscript.

Funding: This work was financially supported by Grant LIDER 46/0185/L-9/17/NCBR/2018.

Acknowledgments: In this section you can acknowledge any support given which is not covered by the author contribution or funding sections. This may include administrative and technical support, or donations in kind (e.g., materials used for experiments).

Conflicts of Interest: The authors declare no conflict of interest. 


\section{References}

1. The Brewers of Europe. Beer Statistics; The Brewers of Europe: Brussels, Belgium, 2018.

2. Brewers Association National Beer Sales and Production Data. Available online: https://www.brewersassociation. org/statistics/national-beer-sales-production-data/ (accessed on 23 December 2019).

3. Alltech. Craft Beer Survey Carried out with The Brewers Journal; Alltech: Brentwood, TN, USA, 2017.

4. Trummer, J.; Poreda, A.; Berski, W. The effect of malting on green lentils and their suitability for wort production. Ferment. FRUITS Veg. Ind. 2019, 10, 14-18. [CrossRef]

5. Duliński, R.; Zdaniewicz, M.; Pater, A.; Żyła, K. Impact of Two Commercial Enzymes on the Release of Inositols, Fermentable Sugars, and Peptides in the Technology of Buckwheat Beer. J. Am. Soc. Brew. Chem. 2019, 77, 119-125. [CrossRef]

6. Cioch-Skoneczny, M.; Zdaniewicz, M.; Pater, A.; Skoneczny, S. Impact of triticale malt application on physiochemical composition and profile of volatile compounds in beer. Eur. Food Res. Technol. 2019, 245, 1431-1437. [CrossRef]

7. Klose, C.; Mauch, A.; Wunderlich, S.; Thiele, F.; Zarnkow, M.; Jacob, F.; Arendt, E.K.; Brew, J.I. Brewing with 100\% Oat Malt. J. Inst. Brew. 2011, 117, 411-421. [CrossRef]

8. Moirangthem, K.; Jenkins, D.; Ramakrishna, P.; Rajkumari, R.; Cook, D. Indian black rice: A brewing raw material with novel functionality. J. Inst. Brew. 2020, 126, 35-45. [CrossRef]

9. Martínez, A.; Vegara, S.; Herranz-López, M.; Martí, N.; Valero, M.; Micol, V.; Saura, D. Kinetic changes of polyphenols, anthocyanins and antioxidant capacity in forced aged hibiscus ale beer. J. Inst. Brew. 2017, 123, 58-65. [CrossRef]

10. Hutzler, M.; Koob, J.; Riedl, R.; Schneiderbanger, H.; Mueller-Auffermann, K.; Jacob, F. Yeast Identification and Characterization; Elsevier Ltd.: Amsterdam, The Netherlands, 2015; ISBN 9781782423492.

11. Hranilovic, A.; Gambetta, J.M.; Schmidtke, L.; Boss, P.K.; Grbin, P.R.; Masneuf-Pomarede, I.; Bely, M.; Albertin, W.; Jiranek, V. Oenological traits of Lachancea thermotolerans show signs of domestication and allopatric differentiation. Sci. Rep. 2018, 8,1-13. [CrossRef]

12. Michel, M.; Meier-Dörnberg, T.; Jacob, F.; Methner, F.J.; Wagner, R.S.; Hutzler, M. Review: Pure non-Saccharomyces starter cultures for beer fermentation with a focus on secondary metabolites and practical applications. J. Inst. Brew. 2016, 122, 569-587. [CrossRef]

13. Canonico, L.; Agarbati, A.; Comitini, F.; Ciani, M. Torulaspora delbrueckii in the brewing process: A new approach to enhance bioflavour and to reduce ethanol content. Food Microbiol. 2016, 56, 45-51. [CrossRef]

14. Canonico, L.; Comitini, F.; Ciani, M. Torulaspora delbrueckii contribution in mixed brewing fermentations with different Saccharomyces cerevisiae strains. Int. J. Food Microbiol. 2017, 259, 7-13. [CrossRef]

15. Michel, M.; Kopecka, J.; Meier-Dörnberg, T.; Zarnkow, M.; Jacob, F. Screening for new brewing yeasts in the non- Saccharomyces sector with Torulaspora delbrueckii as model. Yeast 2016, 33, 129-144. [CrossRef]

16. Holt, S.; Mukherjee, V.; Lievens, B.; Verstrepen, K.J.; Thevelein, J.M. Bioflavoring by non-conventional yeasts in sequential beer fermentations. Food Microbiol. 2018, 72, 55-66. [CrossRef]

17. Canonico, L.; Galli, E.; Ciani, E.; Comitini, F.; Ciani, M. Exploitation of three non-conventional yeast species in the brewing process. Microorganisms 2019, 7. [CrossRef]

18. Bellut, K.; Michel, M.; Hutzler, M.; Zarnkow, M.; Jacob, F.; De Schutter, D.P.; Daenen, L.; Lynch, K.M.; Zannini, E.; Arendt, E.K. Investigation into the Potential of Lachancea fermentati Strain KBI 12.1 for Low Alcohol Beer Brewing. J. Am. Soc. Brew. Chem. 2019, 77, 157-169.

19. Domizio, P.; House, J.F.; Joseph, C.M.L.; Bisson, L.F.; Bamforth, C.W. Lachancea thermotolerans as an alternative yeast for the production of beer. J. Inst. Brew. 2016, 122, 599-604. [CrossRef]

20. Kurtzman, C.P. Phylogenetic circumscription of Saccharomyces, Kluyveromyces and other members of the Saccharomycetaceae, and the proposal of the new genera Lachancea, Nakaseomyces, Naumovia, Vanderwaltozyma and Zygotorulaspora. FEMS Yeast Res. 2003, 4, 233-245. [CrossRef]

21. Banilas, G.; Sgouros, G.; Nisiotou, A. Development of microsatellite markers for Lachancea thermotolerans typing and population structure of wine-associated isolates. Microbiol. Res. 2016, 193, 1-10. [CrossRef]

22. Benito, S. The impacts of Lachancea thermotolerans yeast strains on winemaking. Appl. Microbiol. Biotechnol. 2018, 102, 6775-6790. [CrossRef]

23. Hittinger, C.T.; Steele, J.L.; Ryder, D.S. Diverse yeasts for diverse fermented beverages and foods. Curr. Opin. Biotechnol. 2018, 49, 199-206. [CrossRef] 
24. Osburn, K.; Amaral, J.; Metcalf, S.R.; Nickens, D.M.; Rogers, C.M.; Sausen, C.; Caputo, R.; Miller, J.; Li, H.; Tennessen, J.M.; et al. Primary souring: A novel bacteria-free method for sour beer production. Food Microbiol. 2018, 70, 76-84. [CrossRef]

25. The National Institute of Standards and Technology (NIST). Available online: http://webbook.nist.gov/ chemistry/ (accessed on 23 December 2019).

26. Satora, P.; Semik-Szczurak, D.; Tarko, T.; Bułdys, A. Influence of Selected Saccharomyces and Schizosaccharomyces Strains and Their Mixed Cultures on Chemical Composition of Apple Wines. J. Food Sci. 2018, 83, 424-431. [CrossRef]

27. Analytica EBC, European Brewery Convention; Verlag Hans Carl Getränke-Fachverlag: Nürnberg, Germany, 1998.

28. Porter, T.J.; Divol, B.; Setati, M.E. Investigating the biochemical and fermentation attributes of Lachancea species and strains: Deciphering the potential contribution to wine chemical composition. Int. J. Food Microbiol. 2019, 290, 273-287. [CrossRef]

29. Gobbi, M.; Comitini, F.; Domizio, P.; Romani, C.; Lencioni, L.; Mannazzu, I.; Ciani, M. Lachancea thermotolerans and Saccharomyces cerevisiae in simultaneous and sequential co-fermentation: A strategy to enhance acidity and improve the overall quality of wine. Food Microbiol. 2013, 33, 271-281. [CrossRef]

30. Balikci, E.K.; Tanguler, H.; Jolly, N.P.; Erten, H. Influence of Lachancea thermotolerans on cv. Emir wine fermentation. Yeast 2016, 33, 313-321. [CrossRef]

31. Du Plessis, H.W.; du Toit, M.; Hoff, J.W.; Hart, R.S.; Ndimba, B.K.; Jolly, N.P. Characterisation of non-Saccharomyces yeasts using different methodologies and evaluation of their compatibility with malolactic fermentation. S. Afr. J. Enol. Vitic. 2017, 38, 46-63. [CrossRef]

32. Comitini, F.; Gobbi, M.; Domizio, P.; Romani, C.; Lencioni, L.; Mannazzu, I.; Ciani, M. Selected non-Saccharomyces wine yeasts in controlled multistarter fermentations with Saccharomyces cerevisiae. Food Microbiol. 2011, 28, 873-882. [CrossRef]

33. Benito, Á.; Calderón, F.; Benito, S. Combined use of S. pombe and L. thermotolerans in winemaking. Beneficial effects determined through the study of wines' analytical characteristics. Molecules 2016, 21. [CrossRef]

34. Kapsopoulou, K.; Kapaklis, A.; Spyropoulos, H. Growth and fermentation characteristics of a strain of the wine yeast Kluyveromyces thermotolerans isolated in Greece. World J. Microbiol. Biotechnol. 2005, 21, 1599-1602. [CrossRef]

35. Morales, M.L.; Fierro-Risco, J.; Ríos-Reina, R.; Ubeda, C.; Paneque, P. Influence of Saccharomyces cerevisiae and Lachancea thermotolerans co-inoculation on volatile profile in fermentations of a must with a high sugar content. Food Chem. 2019, 276, 427-435. [CrossRef]

36. Kutyna, D.R.; Varela, C.; Henschke, P.A.; Chambers, P.J.; Stanley, G.A. Microbiological approaches to lowering ethanol concentration in wine. Trends Food Sci. Technol. 2010, 21, 293-302. [CrossRef]

37. Varela, C.; Dry, P.R.; Kutyna, D.R.; Francis, I.L.; Henschke, P.A.; Curtin, C.D.; Chambers, P.J. Strategies for reducing alcohol concentration in wine. Aust. J. Grape Wine Res. 2015, 21, 670-679. [CrossRef]

38. Callejo, M.J.; García Navas, J.J.; Alba, R.; Escott, C.; Loira, I.; González, M.C.; Morata, A. Wort fermentation and beer conditioning with selected non-Saccharomyces yeasts in craft beers. Eur. Food Res. Technol. 2019, 245, 1229-1238. [CrossRef]

39. Shekhawat, K.; Porter, T.J.; Bauer, F.F.; Setati, M.E. Employing oxygen pulses to modulate Lachancea thermotolerans-Saccharomyces cerevisiae Chardonnay fermentations. Ann. Microbiol. 2018, 68, 93-102. [CrossRef]

40. Klopper, B.W.J.; Angelino, S.A.G.F.; Tuning, B.; Vermeire, H.A. Centenary Review Organic Acids and Glycerol in Beer. J. Inst. Brew. 1986, 92, 225-228. [CrossRef]

41. Kapsopoulou, K.; Mourtzini, A.; Anthoulas, M.; Nerantzis, E. Biological acidification during grape must fermentation using mixed cultures of Kluyveromyces thermotolerans and Saccharomyces cerevisiae. World J. Microbiol. Biotechnol. 2007, 23, 735-739. [CrossRef]

42. Pugh, T.A.; Maurer, J.M.; Pringle, A.T. The impact of wort nitrogen limitation on yeast fermentation performance and diacetyl. Master Brew. Assoc. Am. 1997, 34, 189.

43. Hill, A.E.; Stewart, G.G. Free amino nitrogen in brewing. Fermentation 2019, 5. [CrossRef]

44. Shimizu, H.; Mizuno, S.; Hiroshima, T.; Shioya, S. Effect of carbon and nitrogen additions on consumption activity of apparent extract of yeast cells in a brewing process. J. Am. Soc. Brew. Chem. 2002, 60, 163-169. [CrossRef] 
45. Lekkas, C.; Hill, A.E.; Stewart, G.G. Extraction of FAN from malting barley during malting and mashing. J. Am. Soc. Brew. Chem. 2014, 72, 6-11.

46. Evans, D.E.; Goldsmith, M.; Redd, K.S.; Nischwitz, R.; Lentini, A. Impact of mashing conditions on extract, its fermentability, and the levels of wort free amino nitrogen (FAN), $\beta$-glucan, and lipids. J. Am. Soc. Brew. Chem. 2012, 70, 39-49. [CrossRef]

47. De Rouck, G.; Jaskula, B.; De Causmaecker, B.; Malfliet, S.; Van Opstaele, F.; De Clippeleer, J.; De Brabanter, J.; De Cooman, L.; Aerts, G. The influence of very thick and fast mashing conditions on wort composition. J. Am. Soc. Brew. Chem. 2013, 71, 1-14. [CrossRef]

48. Psota, V. Free amino nitrogen in sweet wort made from barley varieties tested in the Czech Republic. Kvas. Prum. 2019, 65, 142-148. [CrossRef]

49. Stewart, G.G.; Russell, I.; Anstruther, A. Handbook of Brewing, 3rd ed.; CRC Press: Boca Raton, FL, USA, 2017.

50. Butzke, C. Survey of yeast assimilable nitrogen status in musts from California, Oregon, and Washington. Am. J. Enol. Vitic. 1998, 49, 220-224.

51. Brewers Association. Malting Barley Characteristics for Craft Brewers Executive Summary; Brewers Association: Boulder, CO, USA, 2015; pp. 1-6.

52. Capece, A.; Romaniello, R.; Siesto, G.; Romano, P. Conventional and non-conventional yeasts in beer production. Fermentation 2018, 4. [CrossRef]

53. Jaskula-Goiris, B.; De Causmaecker, B.; De Rouck, G.; De Cooman, L.; Aerts, G. Detailed multivariate modeling of beer staling in commercial pale lagers. Brew. Sci. 2011, 64, 119-139.

54. De Rouck, G.; De Clippeleer, J.; Poiz, S.; De Cock, J.; van Waesberghe, J.; De Cooman, L.; Aerts, G. Prolonged Flavour Stability by Production of Beer with Low Residual FAN Using Active Dry Yeast. In Proceedings of the 31st Congress of the European Brewery Convention, Venice, Italy, 6-10 May 2007; pp. 455-467.

55. Holt, S.; Miks, M.H.; De Carvalho, B.T.; Foulquié-Moreno, M.R.; Thevelein, J.M. The molecular biology of fruity and floral aromas in beer and other alcoholic beverages. FEMS Microbiol. Rev. 2019, 43, 193-222. [CrossRef]

56. Budroni, M.; Zara, G.; Ciani, M.; Comitini, F. Saccharomyces and Non-Saccharomyces Starter Yeasts. Brew. Technol. InTech 2017, 20.

57. Saerens, S.M.G.; Delvaux, F.; Verstrepen, K.J.; Van Dijck, P.; Thevelein, J.M.; Delvaux, F.R. Parameters affecting ethyl ester production by Saccharomyces cerevisiae during fermentation. Appl. Environ. Microbiol. 2008, 74, 454-461. [CrossRef]

58. Ilc, T.; Werck-Reichhart, D.; Navrot, N. Meta-analysis of the core aroma components of grape and wine aroma. Front. Plant Sci. 2016, 7. [CrossRef]

59. Rybacek, V. Hop Production (Developments in Crop Science 16); Elsevier Publishing Company: Amsterdam, The Netherlands; New York, NY, USA, 1991.

60. De Almeida, N.E.C.; De Aguiar, I.; Cardoso, D.R. Mechanism of hop-derived terpenes oxidation in beer. J. Braz. Chem. Soc. 2015, 26, 2362-2368. [CrossRef]

61. King, A.J.; Dickinson, J.R. Biotransformation of hop aroma terpenoids by ale and lager yeasts. FEMS Yeast Res. 2006, 3, 53-62. [CrossRef]

62. Walker, G.M. Magnesium as a Stress-Protectant for Industrial Strains of Saccharomyces cerevisiae. J. Am. Soc. Brew. Chem. 1998, 56, 109-113. [CrossRef]

63. Walker, G.M.; Birch, R.M.; Chandrasena, G.; Maynard, A.I.; Sciences, L. Magnesium, Calcium, and Fermentative Metabolism in Industrial Yeasts. J. Am. Soc. Brew. Chem. 1996, 54, 13-18. [CrossRef]

64. Jones, R.P.; Greenfield, P.F. Ethanol and the fluidity of the yeast plasma membrane. Yeast 1987, 3, $223-232$. [CrossRef]

65. Bromberg, S.K.; Bower, P.A.; Fehring, J.; Gerber, L.; Lau, V.L.; Tata, M. Requirements for Zin, Manganese, Calcium in wort. J. Am. Soc. Brew. Chem. 1997, 55, 123-128.

66. Chandrasena, G.; Walker, G.M.; Sciences, L.; Dundee, A. Use of Response Surfaces to Investigate Metal Ion Interactions in Yeast Fermentations. J. Am. Soc. Brew. Chem. 1997, 55, 24-29. [CrossRef]

(C) 2020 by the authors. Licensee MDPI, Basel, Switzerland. This article is an open access article distributed under the terms and conditions of the Creative Commons Attribution (CC BY) license (http://creativecommons.org/licenses/by/4.0/). 